\title{
Desenvolvendo o pensamento computacional no ensino fundamental com Arduino e Scratch
}

\author{
Amanda C. Pereira ${ }^{1}$, Matheus E. Franco ${ }^{1}$ \\ ${ }^{1}$ Departamento de Computação - IFSULDEMINAS- Campus Machado \\ CEP - 37.750-000 - MG - Brasil \\ amanda.cferreira@hotmail.com, matheus.franco@ifsuldeminas.edu.br
}

\begin{abstract}
In despite of the frequent use of technological resources part of the population does not understand the basic concepts of computing, being subjected as passive users. In this way, it is important to develop a little explored intellectual capacity: computational thinking, which refers to the ability to solve problems efficiently and systematically. The present project copes with the proposal of a methodology for the development of computational thinking in young people. The results were satisfactory since the students demonstrated a positive return on what they were taught, demonstrating that they felt motivated to learn something new that goes beyond the basic school curriculum.
\end{abstract}

Resumo: Apesar do frequente uso dos recursos tecnológicos parte da população não compreende os conceitos básicos da computação, sujeitando-se como usuários passivos. Desta maneira, é importante desenvolver uma capacidade intelectual pouco explorada: o pensamento computacional. $O$ mesmo se refere à capacidade de solucionar problemas de forma eficiente e sistemática. $O$ presente trabalho apresenta uma metodologia para o desenvolvimento do pensamento computacional em jovens. Os resultados alcançados foram satisfatórios, já que os estudantes mostraram um retorno positivo a respeito do que lhes foi ensinado, demonstrando que se sentiram motivados ao aprender algo novo que vai além do currículo escolar básico.

\section{Introdução}

Apesar da presença constante da tecnologia em nosso dia a dia e da nossa dependência dos meios computacionais, para realizar as mais triviais tarefas, há uma carência no interesse e no conhecimento por parte da população neste assunto. De acordo Resnick et al. (2009), são poucas as pessoas que compreendem os fundamentos por trás de tais tecnologias. Portanto, é como se pudessem "ler", pelo fato de serem capazes de interagir com tais utilitários, mas não "escrever", pelo fato de não possuírem habilidades para inventar e criar com essa nova mídia. Tal ocorrência pode estar relacionada ao fato de que estes indivíduos não tiveram acesso a esse tipo de conhecimento. Segundo Valente (2016), no Brasil, a computação ainda é pouco explorada na Educação Básica e seus fundamentos, muitas vezes, acabam por ficar restrito apenas para aqueles que optam por cursos técnicos ou graduação na área.

De acordo com ACM Model Curriculum for K-12 Computer Science (CSTA, 2011), existe a necessidade dos departamentos de educação reverem seus currículos para melhor educar os jovens, introduzindo conceitos fundamentais da computação aos alunos 
desde o ensino fundamental, pois isso estimula o desenvolvimento do pensamento crítico e computacional.

Wing (2006) salienta que o pensamento computacional é uma habilidade viável a todos, sendo um método que engloba a resolução de problemas, projeção de sistemas, e compreensão do comportamento humano, por meio da abstração dos conceitos fundamentais da ciência da computação. Para que o aluno inicie o desenvolvimento do pensamento computacional é necessária à inserção de conceitos computacionais na Educação Básica. Uma maneira de se introduzir esses conceitos pode ser utilizando as ferramentas Scratch e Arduino.

Segundo Resnick et al. (2009), o software Scratch trata-se de um ambiente de programação em blocos, que permite a criação de algoritmos sem a necessidade de conhecer uma linguagem de programação especifica. O Arduino, segundo Banzi (2009), se trata de uma placa de entrada e saída, que quando conectados a ela sensores a atuadores, possibilita à criação de diversos projetos eletrônicos.

O intuito deste trabalho é propor uma metodologia para desenvolver o pensamento computacional na Educação Básica, introduzindo conceitos fundamentais da computação sem depender de uma linguagem de programação em particular, utilizando o Scratch para Arduino, no qual, segundo Mélo et al. (2011), se trata de uma modificação Scratch com blocos de programação específicos para atuar sobre o Arduino, e integrar esses conceitos ao Arduino, fazendo com que seja possível vislumbrar a aplicação de tais conceitos de uma maneira mais concreta.

\section{Materiais e Métodos}

A metodologia proposta consiste na estruturação de um curso. Para sua avaliação o curso intitulado "Introdução à lógica de programação e automação com o Scratch e Arduino", foi aplicado em uma escola da rede pública de ensino da cidade de Poço Fundo-MG.

O curso oferecido foi extra turno, em aulas semanais de 4 horas, totalizando 40 horas, e teve como público alvo alunos do ensino fundamental. A equipe escolar apresentou o curso aos alunos $7^{\circ}, 8^{\circ}$ e $9^{\circ}$ e coletou os interessados. Posteriormente, a mesma selecionou, por mérito, os alunos com as maiores notas em matemática, tendo em vista a direta relação desta disciplina com os conteúdos a serem propostos. $\mathrm{O}$ curso iniciou-se com um total de 22 estudantes, sendo que destes, 20 concluíram o mesmo.

O curso constitui-se da seguinte forma: apresentar aos alunos conceitos básicos da informática que envolvem hardware e software; introduzir conceitos relacionados a lógica de programação e criação de algoritmo no Scratch e criação de projetos com

o Arduino. Ao término do curso os alunos deveriam apresentar em uma feira de ciências projetos com o Scratch e o Arduino criados por eles próprios a fim de consolidar os conteúdos apresentados. Os materiais utilizados durante as aulas, os planos de aula, os tópicos abordados nas aulas e as descrições das aulas, incluindo a descrição dos projetos criados em Arduino no decorrer das mesmas e os projetos criados pelos alunos, estão

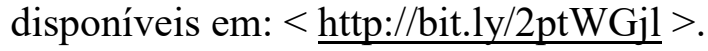

A fim de avaliar o conhecimento dos alunos, anteriormente e posteriormente ao curso ministrado, foram aplicados dois questionários: o primeiro com o intuito de avaliar o conhecimento prévio dos alunos e o segundo para captar as percepções dos mesmos ao término do curso. Os questionários foram semiestruturados, com opções de comente para 
cada pergunta, na qual foi utilizada a escala de Likert para capturar as percepções em dados numéricos. Os questionários aplicados estão disponíveis em: < http://bit.ly/2FQ53AQ $>$.

Para avaliar a metodologia proposta foi utilizado o procedimento criado por Savi (2011), um modelo para planejar, projetar e avaliar a eficácia da aprendizagem. O modelo de avaliação é baseado em alguns modelos já pré-definidos e a partir destes criou algumas dimensões para avaliar a eficácia da aprendizagem. As dimensões propostas por Savi e as questões que foram formuladas, com suas respectivas dimensões, estão disponíveis em: $<$ http://bit.ly/2FRoSaQ $>$.

\section{Resultados e discussões}

A utilização da metodologia proposta permitiu o estabelecimento de um ambiente de trabalho dinâmico e inovador, contribuindo de forma positiva para atrair a atenção dos alunos, pois a partir do momento que os mesmos chegaram aos primeiros resultados de suas criações e viram seus experimentos em funcionamento despertou-se o interesse dos mesmos, fomentando sua satisfação com os resultados obtidos e perante os novos conhecimentos a eles apresentados.

Com base nas dimensões avaliadas através dos questionários, podemos observar o gráfico radar (Figura 1) que mensura a média de cada dimensão avaliada varia 4 a 5 , de acordo com escala Likert.

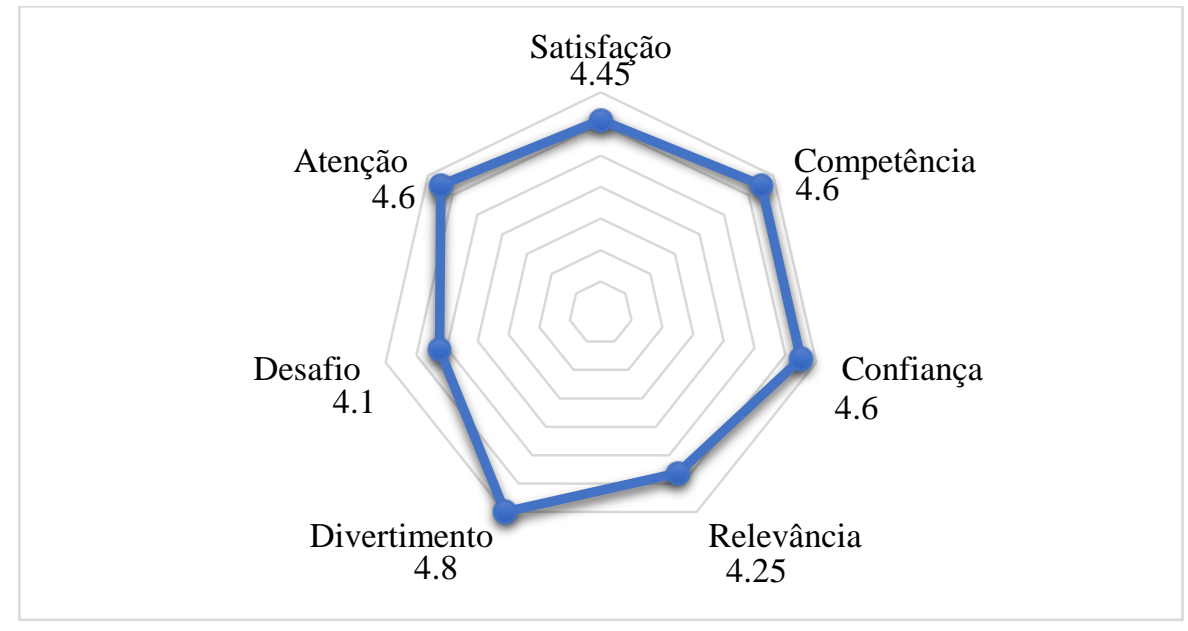

Figura 1. Gráfico radar das avaliações dos alunos

Os resultados foram positivos, pois a união das ferramentas utilizadas culminou por atrair o interesse dos alunos unindo o concreto ao abstrato, tornando plausível ao aluno conhecer as competências algorítmicas e analisar a maneira como essas instruções são inferidas no hardware, tornando os recursos tecnológicos utilizados mais pedagógicos, lúdicos e convidativos, fazendo com que o desenvolvimento do pensamento computacional fosse mais tangível.

De acordo com Wildner, Quartieri e Rehfeldt (2016), manusear objetos tecnológicos que estão de certa forma relacionados à robótica desperta o fascínio e a curiosidade dos alunos e, ao mesmo tempo, a utilização da robótica pode proporcionar motivação e a compreensão de diversos conhecimentos relacionados a computação, 
programação e eletrônica básica. Esses novos conceitos podem se tornar desafiadores para os alunos instigando-os na busca por respostas e se tornando um fator motivador para aprendizagem, podendo cativar a atenção dos mesmos.

\section{Considerações finais}

Foi possível observar que os alunos absorveram boa parte dos conteúdos apresentados, pelo fato de conseguirem criar seus próprios experimentos e organizarem de forma sequencial os esquemas lógicos utilizando os conceitos computacionais. Os resultados dos questionários foram promissores. Todos os processos, desde o desenvolvimento dos projetos, até a criação dos algoritmos em Scratch, exigiu que os estudantes analisassem os problemas propostos pelo professor, promovendo uma organização sistemática de suas ideias. Além disto, foram necessários vários testes dos projetos e com o surgimento de erros era exigida uma reorganização de ideias. Desta forma, os alunos aprimoravam o seu raciocínio lógico, trabalhavam com depuração de erros, enquanto melhoravam sua forma de pensar sistematicamente e faziam isso utilizando os conceitos fundamentais da computação, que envolvem o processo do desenvolvimento do pensamento computacional. Os alunos deram o primeiro passo para compreender as práticas do pensamento computacional e iniciaram o amadurecimento da compreensão da computação, podendo desta maneira atrair novos talentos para a área. Por fim, esta metodologia pode ser utilizada para integrar os conteúdos abordados ao currículo escolar, pois possui carga horária compatível e planos de aula definidos.

\section{Agradecimentos}

Ao Instituto Federal de Educação, Ciência e Tecnologia do Sul de Minas Gerais IFSULDEMINAS pelo apoio concedido.

\section{Referências}

BANZI, M. Getting Started with Arduino. Sebastopol, CA: O’Reilly, 2009.

CSTA - COMPUTER SCIENCE TEACHER ASSOCIATION. CSTA K-12 Computer Science Standards. CSTA Standards Task Force. ACM - Association for Computing Machinery, 2011.

MÉLO, F. E. N., et al. Do Scratch ao Arduino: Uma proposta para o ensino introdutório de programação para cursos superiores de tecnologia. XXXIX Congresso Brasileiro de Educação em Engenharia, Blumenau, SC, 2011.

RESNICK, M. et al. Scratch: programming for all. Communications of the ACM, vol. 52, n. 11, p. 60-67, 2009.

SAVI, R. Avaliação de jogos voltados para a disseminação do conhecimento. Tese Doutorado [s.1.] Universidade Federal de Santa Catarina, 2011.

VALENTE, J. A. Integração do pensamento computacional no currículo da Educação Básica: diferentes estratégias usadas e questões de formação de professores e avaliação do aluno. Revista e-Curriculum, São Paulo, v.14, n.03, p. 864 - 897, 2016.

WILDNER M. C. S.; QUARTIERI M. T.; REHFELDT J. H. Robomat: um recurso robótico para o estudo de áreas e perímetros. Revista Renote, Novas Tecnologias na educação v. 14, n. 2, 2016.

WING, J. M.. Computational thinking. Commun. ACM, 49(3):33-35, 2006. 